\title{
Domestic violence against women in Eastern Sudan
}

\author{
AbdelAziem A Ali ${ }^{1 *}$, Khalid Yassin ${ }^{2}$ and Rawia Omer ${ }^{3}$
}

\begin{abstract}
Background: Violence against women is one of the major public health problems in both developed and developing worlds. The aim of this study was to investigate the prevalence of current (occurred in one year preceding the survey) domestic violence and socio-demographic factors associated with domestic violence against women.

Methods: This was a cross sectional household survey (face to face interview) conducted in Kassala, eastern Sudan, from $1^{\text {st }}$ March to $1^{\text {st }}$ June 2014. Multivariable analyses were performed, Confidence intervals of $95 \%$ were calculated and $P<0.05$ was considered significant.

Results: Of the 1009 women, 33.5\% (338) reported current experience of physical violence and, of these 338 women, 179 (53\%) and $159(47 \%)$ reported moderate and severe form of physical violence respectively. The prevalence of sexual coercion, psychological violence and verbal insult was 17\% (172\1009), 30.1\% (304\1009) and $47.6 \%$ (480\1009) respectively. In the majority of cases, violence was experienced as repeated acts, ie, more than three times per year. For verbal insult 20.1\% (203\480) and 27.5\% (277\480) reported yelling and shouting respectively. Again 251 (24.9\%) and 270 (26.8\%) women reported that they experience divorce threat and second marriage threat respectively. In logistic regression model, husband's education ( $\mathrm{OR}=1.5 ; \mathrm{Cl}=1.0-2.1 ; P=0.015)$, polygamous marriage $(\mathrm{OR}=1.9 ; \mathrm{Cl}=1.3-2.9 ; P=0.000)$, and husband's alcohol consumption $(\mathrm{OR}=13.9 ; \mathrm{Cl}=7.9-25.4$; $P<0.000$ ) were significantly associated with domestic violence.
\end{abstract}

Conclusions: Domestic violence was found to be highly prevalent in eastern Sudan and strongly associated with the educational status, polygamous marriage and husband's alcohol consumption. We recommend more research to include men.

Keywords: Violence, Women, Public, Health, Sudan

\section{Background}

The World Health Organization (WHO) defined domestic violence as "the range of physically, psychologically and sexually coercive acts used against adult and adolescent women by current or former male intimate partners" [1]. Violence against women is one of the major public health problems in both developed and developing worlds. It varies from community to community and the pattern of the violence affected by the different socioeconomic and cultural factors [2]. Worldwide the prevalence of domestic violence against women ranges between $15 \%$ and $71 \%$ [3]. Data on domestic violence is scarce particularly in

\footnotetext{
* Correspondence: abuzianab73@yahoo.com

${ }^{1}$ Faculty of Medicine, Kassala University, Kassala, Sudan

Full list of author information is available at the end of the article
}

developing countries. Many theories can be used to explain the occurrence of domestic violence against women; these include sociological, gender and family system theories $[4,5]$. Sociological theories indicate that low level of education, economic vulnerability, stress and a closed social network increase the risk of partner violence, while the gender theory is indicated by the male being the dominant person in some communities. On the other hand family system theories focus on communication, relationship and problem solving skills of couples in whom violence occurs $[4,5]$.

There is limited data on the prevalence of the domestic violence against women in the sub-Saharan and African countries [6]; however there are a recognized correlation between the domestic violence and various reproductive health problems such as non use of contraception and 
sexually transmitted diseases [7]. Domestic violence is against the religious perception and the Islamic teaching discourages the violence against women. Sudan is one of the largest African countries with different public health problems such as female genital mutilation and teenage pregnancy $[8,9]$. A number of steps have been taken by the government of Sudan to fight violence against women and girls, and it is extremely important to consider them. In 2005 a state plan to combat violence against women was adopted and a new Violence against Women (VAW) Unit was created at the Ministry of Justice [10]. To our knowledge no available data on domestic violence against women in Sudan exists, thus the current study designed and directed to investigate the prevalence rate and sociodemographic factors associated with domestic violence against women in Eastern Sudan aiming to provide the policy makers with fundamental data to reduce the prevalence rate of this practice.

\section{Methods}

\section{Study area and period}

This was a community-based cross sectional household survey conducted in Kassala, eastern Sudan from $1^{\text {st }}$ March to $1^{\text {st }}$ June 2014. Kassala is located in eastern Sudan, $600 \mathrm{~km}$ from Khartoum; it is 42,282 square km, with a population of 1.8 million people. Of these, 440,491 women are of reproductive age. Kassala state bordered two neighboring countries, Eritrea and Ethiopia, with a prominent diversity in culture, religion, language and ethnicity. The state comprises of 6 administrative localities, the responsibilities of the maternal health care services lie with the department of the reproductive health at the ministry of health. There are one referral (tertiary) hospital, two secondary care level hospitals, 13 rural hospitals and 144 primary health centers providing preventive and curative maternal health care services. Kassala state is described by high prevalent rate of illiteracy, child marriage and female genital mutilation [8].

\section{Eligibility criteria}

The study population was all women in Kassala during the study period. Women were eligible to participate in the study if they resided in the study period and they were in the reproductive age (15 - 49 years), also women were eligible if they married for $\geq$ one year and agreed to participate in the study. A total sample size of 1009 women was calculated to be needed using a single population proportion formula, which would provide $80 \%$ power and which assumed $10 \%$ of women would not respond. Multi-stage sampling was used to select the study population. Households were selected by systemic random sampling of the sampling frame obtained from the administrate unit in Kassala. When more than one eligible woman was found in a selected household, one of the women was interviewed randomly. If no eligible woman was encountered in the selected household, the next household on the right was visited.

\section{Data collection and variables}

Ten medical students were selected as interviewers; they had been trained in relationship building, local cultures, language, confidentiality and how to administer the questionnaires. For more security we interviewed the participant during the day activity in the absence of their husbands and this point was considered in the ethical clearance. After obtaining written consent, self structured questionnaires were used to gather data (face to face interview) from the eligible women. We used our own questionnaire which was constructed by the authors to consider different individual issues specific to our environment such as polygamous marriage, threat with divorce and second marriage however the violence items stem from validated and widely used questionnaire (Domestic Violence Questionnaire in Married Women) [11]. We started to fill the questionnaire after explanation of the purpose of the study and making sure the aim of the study was well understood by the participant. Information sought in the questionnaire included sociodemographic characteristics (age, ethnicity, educational level, residence, duration of marriage, parity, occupation, consanguinity, polygamous marriage, number of family members, husband's age, husband's education, occupation and husband's alcohol consumption). We aimed to investigate the prevalence of current (occurred in one year preceding the survey) domestic violence and sociodemographic factors associated with domestic violence against women in eastern Sudan. This violence included physical violence, sexual coercion, psychological violence and verbal insult. Physical violence was measured as moderate (slapping, throwing things, pushing, shoving) or severe (hitting, kicking, dragging, beating, chocking, burning) and sexual coercion was defined as being coerced to perform sexual acts against woman's will and physically forced into sexual intercourse by the husband. Psychological violence was defined as insulting the woman or making her feel bad about herself, belittlement or humiliation in front of others, doing things to scare or intimidate her on purpose, and threats to hurt her or someone she cared about and the verbal insult included yelling, shouting, threat with divorce orland second marriage.

\section{Statistical analysis}

Data were entered into a computer database and SPSS software (SPSS Inc., Chicago, IL, USA, version 16.0). Multivariable analyses were performed. Domestic violence against women was the dependent variable and sociodemographic characteristics were independent variables. 
Confidence intervals of $95 \%$ were calculated and $P<0.05$ was considered significant.

\section{Ethics}

The study approved and received ethical clearance from the Research Board at the Ministry of Health, Kassala State, Eastern Sudan. In this study we followed the WHO guidelines for ethical clearance and written consent. The written consent included the research title, purpose, benefit, participants' right, confidentiality and signature.

\section{Results}

\section{Participants' characteristics}

A total of 1009 women were enrolled and none of them refused to participate in this study. Their mean (SD) age, husband's age and parity was 32.9 (8.1), 42.4 (10.4) and 3.2 (2.4) respectively. The duration of their marriage ranged between 1 to 27 years. Three-quarters of the women $(757 \backslash 1009,75 \%)$ lived in urban community and more than one-third of the women (197\1009, 33.5\%) lived in a polygamous marriage. Almost half $(500 \backslash 1009$, $49.6 \%)$ of the women were of less than secondary level education and $66.1 \%$ (667\1009) were housewives.

\section{Prevalence of domestic violence}

Of the 1009 women, 33.5\% (338) reported current (in one year preceded the survey) experience of physical violence and, of these 338 women, 179 (53\%) and 159 (47\%) reported moderate and severe form of physical violence respectively, Table 1 . Among physical, sexual and psychological violence the most commonly occurring single form was physical violence (33.5\%). The prevalence of sexual coercion, psychological violence

Table 1 Different forms of physical violence among women in Eastern Sudan, 2014

\begin{tabular}{lll}
\hline Form of violence & Number & $\begin{array}{l}\text { Percentage of the } \\
\text { total }(n=338)\end{array}$ \\
\hline $\begin{array}{ll}\text { Moderate forms } \\
\text { Slapping }\end{array}$ & 86 & $25.4 \%$ \\
Throwing things & 60 & 17.8 \\
Pushing & 29 & 8.6 \\
Shoving & 4 & 1.2 \\
Severe forms: & & \\
Hitting & 43 & 12.7 \\
Kicking & 14 & 4.1 \\
Dragging & 32 & 9.5 \\
Beating & 40 & 11.8 \\
Chocking & 20 & 5.9 \\
Burning & 10 & 3 \\
Total & 338 & 100 \\
\hline
\end{tabular}

Data was shown as number and percentage as applicable. and verbal insult was $17 \%$ (172\1009), 30.1\% (304\1009) and $47.6 \%(480 \backslash 1009)$ respectively. In the majority of cases, violence was experienced as repeated acts, ie, more than three times per year, Table 2 . For verbal insult $20.1 \%$ (203\480) and 27.5\% (277\480) reported yelling and shouting respectively. Again 251 (24.9\%) and 270 (26.8\%) women reported that they experience divorce threat and second marriage threat respectively.

\section{Factors associated with domestic violence}

Among the socio-demographic data there were commonalities and difference in the factors associated with the different type of domestic violence against the surveyed women. In logistic regression model, husband's education ( $\mathrm{OR}=1.5 ; \mathrm{CI}=1.0-2.1 ; P=0.015)$, polygamous marriage $(\mathrm{OR}=1.9 ; \mathrm{CI}=1.3-2.9 ; P=<0.001)$, and husband's alcohol consumption $(\mathrm{OR}=13.9 ; \mathrm{CI}=7.9-25.4 ; P<0.00)$ were significantly associated with physical violence, Table 3. While psychological violence was significantly varied with women's education $(\mathrm{OR}=1.2 ; \mathrm{CI}=0.9-1.2 ; P=0.010)$, polygamous marriage $(\mathrm{OR}=1.6 ; \mathrm{CI}=1.1-2.4 ; P=0.006)$ and husband's alcohol consumption $(\mathrm{OR}=4.5 ; \mathrm{CI}=2.8-7.2$; $P=<0.001)$ there was significant statistical association between sexual coercion husband's age $(\mathrm{OR}=1.0$; $\mathrm{CI}=$ 1.0-1.1; $P=0.031)$, polygamous marriage $(\mathrm{OR}=1.7 ; \mathrm{CI}=$ 1.1-2.7; $P=0.009$ ) and husband's alcohol consumption $(\mathrm{OR}=5.6 ; \mathrm{CI}=3.5-9.1 ; P=<0.001)$, Table 4 .

\section{Discussion}

To our knowledge this is the first study to investigate domestic violence against women in Sudan. Domestic violence against women is extremely sensitive issue in our community and it was anticipated to find underestimated prevalence rate. The data was collected by female students who lived in the same state and were well respected and trusted in the community. The current physical violence which this study describes (33.5\%) is comparable with other results from some Asian countries such as Vietnam and India [12]. A report from Iran of 2400 married women found that $15 \%$ experienced physical violence from their husbands in the previous year, $42 \%$ sexual coercion, and $82 \%$ various degrees of

Table 2 Frequency of physical violence per year among women in Eastern Sudan 2014

\begin{tabular}{lll}
\hline Frequency & Number & $\begin{array}{l}\text { Percentage of the } \\
\text { total }(n=338)\end{array}$ \\
\hline Once & 71 & 21 \\
Twice & 52 & 15.4 \\
Thrice & 44 & 13 \\
$>$ Thrice & 171 & 50.6 \\
Total & 338 & 100 \\
\hline
\end{tabular}

Data was shown as number and percentage as applicable. 
Table 3 Factors associated with physical violence against women in Eastern Sudan using multivariable analyses, 2014

\begin{tabular}{llll}
\hline Variable & \multicolumn{3}{l}{ Multivariable analyses } \\
\cline { 2 - 4 } & OR & $\mathbf{9 5 \% ~ C l}$ & $\boldsymbol{P}$-value \\
\hline Women's age, years & 0.1 & $0.9-1.0$ & 0.604 \\
Parity $\geq 3$ & 0.1 & $0.9-1.1$ & 0.302 \\
Husband's age, years & 0.1 & $0.9-1.0$ & 0.165 \\
Duration of marriage $\geq 5$ years & 0.9 & $0.9-1.0$ & 0.646 \\
$1^{\text {st }}$ degree relationship & 1.2 & $0.9-1.7$ & 0.120 \\
Women's education < secondary level & 1.2 & $0.8-1.7$ & 0.248 \\
Women's occupation, housewives & 0.8 & $0.6-1.0$ & 0.231 \\
Husband's education < secondary level & 1.5 & $1.0-2.1$ & 0.015 \\
Rural residence & 1.0 & $0.7-1.4$ & 0.879 \\
Ethnicity, hadandwa tribe & 1.0 & $0.8-1.2$ & 0.635 \\
Family members $\geq 5$ & 0.9 & $0.8-1.0$ & 0.263 \\
Polygamous marriage & 1.9 & $1.3-2.9$ & $<0.001$ \\
Husband's alcohol consumption & 13.9 & $7.6-25.4$ & $<0.001$ \\
\hline
\end{tabular}

Abbreviations: OR Odds Ratio, $\mathrm{Cl}$ confidence interval.

psychological abuse [13]. According to the World Health Organization's multi-country study on violence against women in intimate relationships, the lifetime prevalence of physical or sexual coercion ranges between 15\% and $71 \%$, and past-year prevalence also shows a wide variation $(4 \%-54 \%)$, with the lowest rates found for Japan and the highest for Ethiopia, Peru, and Bangladesh [3].

Our findings indicate poor socio-economic circumstances contribute significantly to domestic violence against women. Sudan is a low-income country with more than 30 million inhabitants. It is a male-dominated society, where husband violence is accepted as a cultural norm and viewed as normal behavior within the families. Although it's against Islamic teachings, domestic violence against wives is often justified by the woman's misbehaviour or disobedience. Moreover in developing countries other factors may be attributed to high prevalence of violence, these include poverty and fear of the mother from divorce because divorce is a social stigma for the mother in our community. Another factor is the social norm which strongly encourages the women to accept the different misbehaviors of the husband. Our findings showed unacceptably high prevalence of psychological insult and sexual coercion and it is of no doubt the different forms of violence give negative impact on the women's life in particular their care after children and community participation [14]. Also our respondents experienced different forms of insults, second marriage threat, verbal and divorce threats. Females are usually the victims in male-dominated societies with less gender equality like Sudan. It is not of great surprise to find high prevalence rate of sexual coercion, psychological insults or other form of violence in the community where there is high prevalence of physical violence. Research has shown that physical violence is often associated with psychological or and sexual coercion [15]. Our results showed significant association between domestic violence against women, husband's alcohol consumption and polygamous marriage. Women living in polygamous marriage and with alcoholic partners expressed greater incidence of troubles and conflict with their husbands and this put them at greater risk of violence. This fact possibly might interpret the association between domestic violence and these two variables. In

Table 4 Factors associated with psychological insult and sexual coercion against women in Eastern Sudan using multivariable analyses, 2014

\begin{tabular}{|c|c|c|c|c|c|c|}
\hline \multirow[b]{2}{*}{ Variable } & \multicolumn{3}{|c|}{ Psychological insult } & \multicolumn{3}{|c|}{ Sexual coercion } \\
\hline & $\overline{\mathrm{OR}}$ & $95 \% \mathrm{Cl}$ & $P$-value & $\overline{\mathrm{OR}}$ & $95 \% \mathrm{Cl}$ & $P$-value \\
\hline Women's age, years & 1.0 & $0.9-1.0$ & 0.539 & 1.0 & $0.9-1.0$ & 0.256 \\
\hline Parity $\geq 3$ & 1.0 & $0.9-1.0$ & 0.848 & 1.0 & $0.9-1.1$ & 0.419 \\
\hline Husband's age, years & 1.0 & $0.9-1.0$ & 0.121 & 1.0 & $1.0-1.1$ & 0.031 \\
\hline Duration of marriage $\geq 5$ years & 0.9 & $0.9-1.0$ & 0.768 & 0.9 & $0.9-1.0$ & 0.102 \\
\hline $1^{\text {st }}$ degree relationship & 1.2 & $0.9-1.7$ & 0.097 & 1.2 & $0.8-1.8$ & 0.216 \\
\hline Women's education < secondary level & 1.5 & $1.1-2.2$ & 0.010 & 1.1 & $0.7-1.7$ & 0.527 \\
\hline Women's occupation, housewives & 0.8 & $0.7-1.0$ & 0.230 & 1.0 & $0.8-1.3$ & 0.738 \\
\hline Husband's education < secondary level & 1.3 & $0.9-1.8$ & 0.088 & 1.4 & $0.9-2.1$ & 0.084 \\
\hline Rural residence & 1.1 & $0.8-1.6$ & 0.435 & 1.0 & $0.6-1.6$ & 0.798 \\
\hline Ethnicity, hadandwa tribe & 1.0 & $0.8-1.3$ & 0.495 & 1.0 & $0.8-1.3$ & 0.755 \\
\hline Family members $\geq 5$ & 0.8 & $0.8-1.0$ & 0.441 & 0.8 & $0.9-1.0$ & 0.166 \\
\hline Polygamous marriage & 1.6 & $1.1-2.4$ & 0.006 & 1.7 & $1.1-2.7$ & 0.009 \\
\hline Husband's alcohol consumption & 4.5 & $2.8-7.2$ & $<0.001$ & 5.6 & $3.5-9.1$ & $<0.001$ \\
\hline
\end{tabular}

Abbreviations: OR Odds Ratio, $\mathrm{Cl}$ confidence interval. 
consistent with study conducted in Pakistan [12], the multivariable analysis in our study showed strong association between husband education and physical violence and between women's education and psychological violence against women, this is in line with what was also been found in other public health study in Bangladesh [16].

We believe that the findings of the current study will help the policy makers to put their strategic plan to fight the practice. Domestic violence was found to be associated with husbands' education, polygamous marriage and husband's alcohol consumption however, causality cannot be determined due to the cross sectional design of the study. The prevalence of domestic violence is possible to be reduced by improving the educational status of the community, advice against alcohol consumption and create a governmental law for the punishment concerning the violence against women. Although the participation was optional, no woman refused to participate in this study, this of no doubt strengthen our findings.

\section{Limitations}

One of the major limitations of this study we asked the women about the current domestic violence (one year preceded the survey) rather than the past life violence. The past-year prevalence rates provide more robust estimates due to the fact that these events have taken place closer in time compared with events that have taken place further in the past and which are easier to forget. Our study is a cross sectional one thus the causality between domestic violence and the associated factors cannot be determined. Furthermore violence in developing and male-dominated societies might occur against daughters and other close relatives; however our study investigated the husband violence against their wives. Also the men were not investigated to understand the magnitude of the problem and why they practice domestic violence against their wives.

\section{Conclusions}

Domestic violence was found to be highly prevalent in eastern Sudan and strongly associated with the educational status, polygamous marriage and husband's alcohol consumption. We recommend more research to include men.

\section{Competing interests}

The authors declare that they have no competing interests.

\section{Author details}

${ }^{1}$ Faculty of Medicine, Kassala University, Kassala, Sudan. ${ }^{2}$ Faculty of Medicine, Alnelain University, Khartoum, Sudan. ${ }^{3}$ Ministry of Health, Kassala State, Kassala, Sudan.

Received: 4 July 2014 Accepted: 24 October 2014

Published: 4 November 2014

References

1. World Health Organization: WHO/WHD Violence Against Women: Priority Health Issue. Geneva: World Health Organization; 1997. WHO document WHO/FRH/WHD/97.8.

2. Logan TK, Walker R, Leukefeld CG: Rural, urban influenced and urban difference among domestic violence arrestees. J Interpers Viol 2001, 16:266-283.

3. Garcia-Moreno C, Jansen H, Ellsberg M, Heise L, Watts CH: WHO Multi-country study on women's Health and Domestic Violence against Women Study Team. Prevalence of intimate partner violence: Findings from the WHO multi-country study on women's health and domestic violence. Lancet 2006, 368(9543):1260-1269.

4. Cunningham A, Jaffe PG, Baker L, Dick T, Malla S, Mazaheri N, Poisson S: Theory-derived Explanation of Male Violence Against Female Partners: Literature Update and Related Implications for Treatment and Evaluation. London, UK: London Family Court Clinic; 1998.

5. Courtenay WH: Constructions of masculinity and their influence on men's well-being: A theory of gender and health. Soc Sci Med 2000, 50(10):1385-1401.

6. Jewkers R, Penn-Kekana L, Levin J, Ratsaka M, Schrieber M: Prevalence of emotional, physical and sexual abuse of women in three South African Provinces. S Afr Med J 2001, 91:421-428.

7. Koenig MA, Lutalo T, Zhao F, Nalugoda F, Mangen FW, Kiwanuka N, Wagman J, Serwadda D, Wawer M, Gray R: Domestic violence in rural Uganda: evidence from a community-bases study. Bull World Health Organ 2003, 81(1):53-60

8. Ali AA, Okud A, Mohammed AA: Prevalence and factors affecting female genital mutilation in eastern Sudan. Int Gynaecol Obstet 2013, 120:288-289.

9. Ali AA, Mohammed AA, Sulaiman MA: Education, poor antenatal care coverage and teenage preganancy and teenage preganancy at Kassala hospital, eastern Sudan. J Public Health Epidemiol 2011, 3(13):642-644.

10. Tønnessen L: Sexual violence in Sudan beyond Darfur - CMI. Chr. Michelsen Institute; 2012. www.cmi.no/file/1939-noref-report.pdf.

11. Indu PV, Remadevi S, Vidhukumar K, Anikumar TV, Subha N: Development and validation of the Domestic Violence Questionnaire in married women aged 18-55 years. Indian J Psychiatry 2011, 53(3):218-223.

12. Ali TS, Asad N, Mogren I, Krantz G: Intimate partner violence in urban Pakistan: prevalence, frequency, and risk factors. Int J Women's Health 2011, 3:105-115.

13. Faramarzi MES, Mosavi S: Prevalence and determinants of intimate partner violence in Babol City, Islamic Republic of Iran. East Mediterr Health J 2005, 11(5-6):870-879.

14. Babu BV, Kar SK: Domestic violence against women in Eastern India: A population-based study on prevalence and related issues. BMC Public Health 2009, 9:129. PubMed: 19426515.

15. Ellsberg M, Pena R, Herrera A, Liljestrand J, Winkvist A: Candies in hell: women's experiences of violence in Nicaragua. Soc Sci Med 2000, 51(11):1595-1610.

16. Naved RT, Azim S, Bhuiya A, Persson LA: Physical violence by husbands: Magnitude, disclosure and help-seeking behavior of women in Bangladesh. Soc Sci Med 2006, 62(12):2917-2929.

\section{Authors' contributions}

AAA carried out the study, participated in the analysis and manuscript drafting. YK and OR participated in analysis and manuscript drafting. All authors read and approved the final manuscript. 